\title{
La tradizione della lirica nel Medioevo romanzo. Problemi di filologia formale, a cura di Lino Leonardi
}

\section{Walter Meliga}

\section{(2) OpenEdition}

1 Journals

\section{Edizione digitale}

URL: http://journals.openedition.org/studifrancesi/335

DOI: 10.4000/studifrancesi.335

ISSN: 2421-5856

\section{Editore}

Rosenberg \& Sellier

\section{Edizione cartacea}

Data di pubblicazione: 1 aprile 2015

Paginazione: 123

ISSN: 0039-2944

\section{Notizia bibliografica digitale}

Walter Meliga, «La tradizione della lirica nel Medioevo romanzo. Problemi di filologia formale, a cura di Lino Leonardi », Studi Francesi [Online], 175 (LIX | I) | 2015, online dal 01 avril 2015, consultato il 18 septembre 2020. URL : http://journals.openedition.org/studifrancesi/335; DOI : https://doi.org/ 10.4000/studifrancesi.335

Questo documento è stato generato automaticamente il 18 settembre 2020.

\section{(c) (1)}

Studi Francesi è distribuita con Licenza Creative Commons Attribuzione - Non commerciale - Non opere derivate 4.0 Internazionale. 


\title{
La tradizione della lirica nel Medioevo romanzo. Problemi di filologia formale, a cura di Lino Leonardi
}

\author{
Walter Meliga
}

\section{NOTIZIA}

La tradizione della lirica nel Medioevo romanzo. Problemi di filologia formale, a cura di Lino LEONARDI, atti del Convegno Internazionale Firenze-Siena, 12-14 novembre 2009, Firenze, Edizioni del La tradizione della lirica nel Medioevo romanzo. Galluzzo, 2011 («Archivio Romanzo», 21), pp. 476.

1 Il convegno ha come oggetto lo studio diacronico dei canzonieri lirici romanzi e dei loro rapporti all'interno delle rispettive tradizioni. Della lirica d'oil trattano il contributo di M. S. LANNUTTI, Sulle raccolte miste di lirica galloromanza (pp. 153-178), che tratta in particolare dei canzonieri con sezioni in lingua d'oc, e quello di L. BARBIERI, Contaminazioni, stratificazioni e ricerca dell'originale nella tradizione manoscritta dei trovieri (pp. 179-240), che affronta varie questioni della tradizione dei trovieri, in particolare per quanto riguarda il problema della contaminazione. 